\title{
Social Regulation of Adult Neurogenesis in a Eusocial Mammal
}

by

Diana Peragine

A thesis submitted in conformity with the requirements

for the degree of Master of Arts

Graduate Department of Psychology

University of Toronto

(C) Copyright by Diana Peragine 2013 


\title{
Social Regulation of Adult Neurogenesis in a Eusocial Mammal
}

\author{
Diana Peragine \\ Master of Arts \\ Graduate Department of Psychology \\ University of Toronto
}

2013

\section{Abstract}

The present study examined social status and adult neurogenesis in the naked mole rat. These animals live in large colonies with a strict reproductive dominance hierarchy; one female and 1-3 males breed, while other members are subordinate and reproductively suppressed. We examined whether social status affects doublecortin (DCX; a marker for immature neurons) immunoreactivity in the dentate gyrus, piriform cortex (PCx), and basolateral amygdala (BLA) by comparing breeders to subordinates. We also examined subordinates removed from their colony and paired with opposite- or same-sex conspecifics for 6 months. Breeders had reduced DCX immunoreactivity in all areas, with BLA effects confined to females. Effects of housing condition were region-specific, with higher PCx DCX immunoreactivity observed in oppositethan same-sex paired subordinates regardless of gonadal status. The opposite pattern was observed in the BLA. Future work will clarify whether findings are attributable to status differences in stress, behavioural plasticity, or life stage. 


\section{Acknowledgments}

A special note of thanks goes to my advisor, Dr. Melissa Homes, for her guidance and honesty, and for "infecting" me with the spark to aspire and pursue knowledge. Her enthusiasm and constant support made this process transformative and personal, but never lonely.

I am deeply grateful to Dr. Robert Gerlai and Dr. Alison Fleming for serving on my thesis committee, and for their valuable suggestions on the work presented here. I am perhaps even more thankful for their wisdom and captivating story-telling, which helped cement my interest in biopsychology, and weighed heavily on my decision to pursue graduate research.

I would also like to thank all those in the Holmes and Monks labs that broadened the value of this research, challenged my ideas, and supplied sanity-saving banter on the joys and travails of graduate life.

Finally, thank you to all my friends and family, who are peripheral to my professional life, but central to all else. 


\section{Table of Contents}

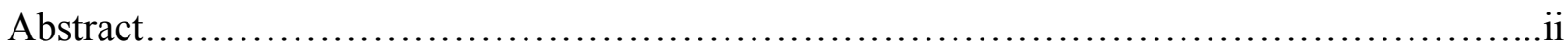

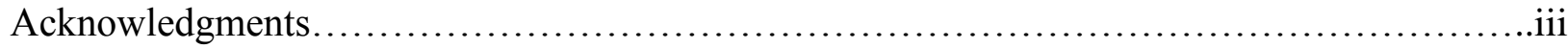

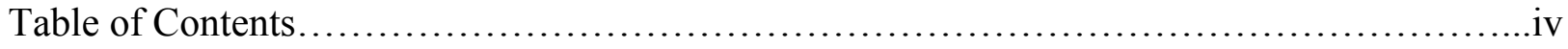

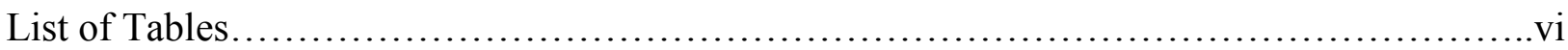

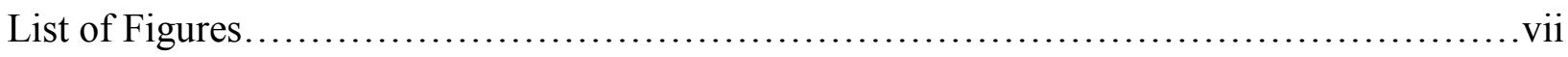

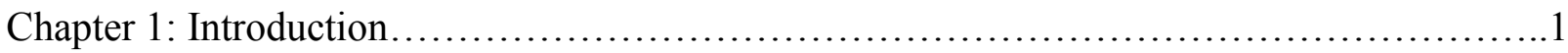

1.1 Towards an Understanding of Experience-dependent Plasticity...................

1.2 Adult Neurogenesis.........................................................

1.3 Social Control of Adult Neurogenesis..............................................2

1.4 Gonadal Control of Adult Neurogenesis ...................................

1.5 Neurogenesis in Noncanonical Neurogenic Regions..........................6

1.6 The Naked Mole-rat: A Eusocial Mammal.......................................6

1.7 The Present Study..................................................

2 Chapter 2: Methods...........................................................

2.1 Animals and Experimental Design......................................

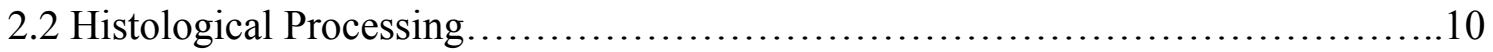

2.3 Quantification......................................................10

2.4 Data Analyses.....................................................11

3 Chapter 3: Results..................................................... 12 
3.1 DCX Expression in the Dentate Gyrus....................................... 12

3.2 DCX Expression in the Piriform Cortex..................................... 12

3.3 DCX Expression in the Basolateral Amygdala.................................13

4 Chapter 4: Discussion..................................................... 14

4.1 Summary.............................................................

4.2 Adult Neurogenesis and Social Factors.................................. 14

4.3 Adult Neurogenesis and Gonadal Factors................................... 18

4.4 Conclusion........................................................... 19

References................................................................20

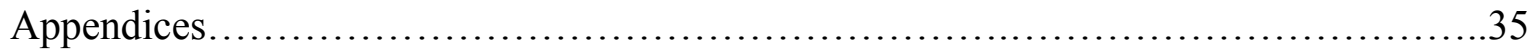

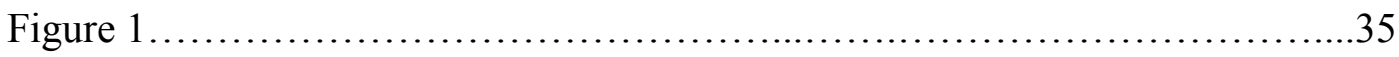

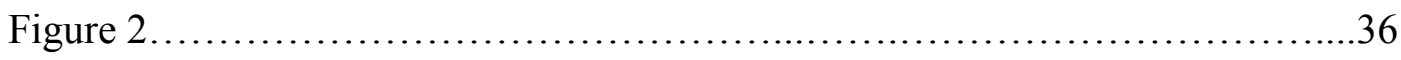

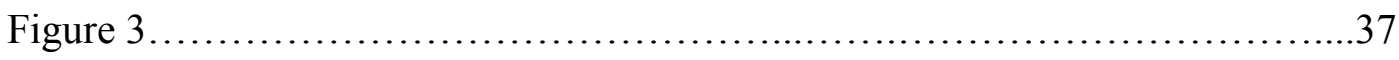

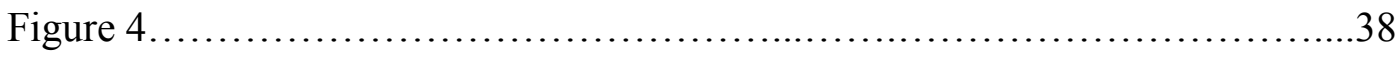

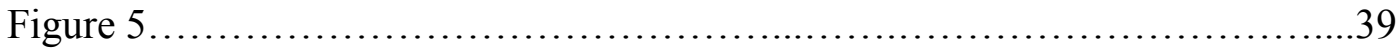




\section{List of Figures}

Figure 1. Photomicrographs of DCX immunoreactivity in DG.......................... 35

Figure 2. Photomicrographs of DCX immunoreactivity in PCx and BLA...................36

Figure 3. Mean (+SEM) density of DCX label in DG.................................... 37

Figure 4. Mean (+SEM) density of DCX label in PCx................................. 38

Figure 5. Mean (+SEM) density of DCX label in BLA............................. 39 


\section{Chapter 1 \\ Introduction}

\subsection{Towards an Understanding of Experience-dependent Plasticity: Neurogenesis and Social Behaviour}

Social interactions can have striking effects on physiology, behaviour, and brain plasticity. While the effects of social interactions on neuronal activation, neurotransmitter release, and receptor distribution have been well-established (E.g., Matsuoka et al., 2002; Pfaus \& Heeb, 1997; Flanagan-Cato et al., 2006; Cushing \& Wynne-Edwards, 2006 ), their influence on neurogenesis is less clear (Lieberwirth and Wang, 2012). Adult neurogenesis is the birth of new neurons, which continues postnatally and into adulthood in the brains of several mammalian species, including humans. New cells integrate into hippocampal and olfactory circuits, leading to enhanced synaptic plasticity (Nissant et al., 2009), increased responsiveness to stimuli (Magavi et al., 2005), and improved learning and memory processes (Shors et al., 2001; Snyder et al., 2005; Winocur et al., 2006; Deng et al., 2009; Rochefort et al., 2002; Sultan et al., 2010). Pioneering work on adult neurogenesis centered on song learning in birds (Goldman and Nottebohm, 1983; Paton and Nottebohm, 1984), suggesting a role for adult-born neurons in the support of socially-relevant behaviours. Despite this connection, relatively sparse research has addressed the functional and regulatory relationships between adult neurogenesis and social behaviour.

\subsection{Adult Neurogenesis}

Work on the timing and sequence of postnatal neurogenesis was piloted by Joseph Altman, who proposed in 1962 that new cells are born within the mature CNS. Using tritiated thymidine, a nucleotide taken up by cells synthesizing DNA prior to cell division, Altman and colleagues observed that new cells are produced predominantly in the hippocampal dentate gyrus (DG) and subventricular zone (SVZ) of the mature mammalian brain (Altman, 1963; 1969; Altman \& Das, 1965a; Altman \& Das, 1965b). Evidence for adult neurogenesis in other vertebrate species accumulated over the next three decades, but most of what we know about neuronal production in the postnatal brain comes from autoradiographic studies of traditional laboratory rodents. This body of work revolutionized our conception of the developing brain and the degree of plasticity that can be induced by experience. 
Within the SVZ, ependymal cells and astrocytes continue to self-renew throughout life (Chiasson et al., 1999). Guided by the flow of cerebrospinal fluid, the vast majority of SVZ-born neuroblasts travel along the rostral migratory stream to the olfactory bulb $(\mathrm{OB})$, where they differentiate into granule and periglomular interneurons (Doetsch et al., 1997; Sawamoto et al., 2006). By contrast, cells born from progenitors in the SGZ travel only a short distance to the adjacent granule cell layer (GCL), where they mature into granule cells and restructure the area according to the current environment. This process can be modified at several stages, including progenitor proliferation, neural differentiation, maturation, and integration into functional neural networks (Ming and Song, 2005), with clear ramifications for cognitive processing and responding.

\subsection{Social Control of Adult Neurogenesis}

Research conducted to date on neurogenesis and social variables has been dominated by two approaches. One line of research highlights how distinct aspects of social life (E.g., sexual encounters, gestation, parenthood, and chemosensory cues conveying the sex, status and health of conspecifics) regulate the birth, fate, and integration of adult-born neurons. For example, mating encounters or exposure to opposite-sex chemosensory cues up-regulate cell proliferation in the rodent DG and SVZ (Smith et al., 2001; Larsen et al., 2008; Leuner et al., 2010), as well as the survival and differentiation of newborn neurons in the DG and olfactory bulb (OB) (Baudoin et al., 2005; Mak et al., 2007; Larsen et al., 2008; Oboti et al., 2009; Corona et al., 2011). Conversely, aversive interactions with dominant and aggressive conspecifics reduce cell proliferation and survival in the DG, suggesting that hippocampal neurogenesis is sensitive to status and social threat cues (Gould et al., 1997; 1998; Czeh et al., 2001; Van der Hart et al., 2002; Kozorovitskiy and Gould, 2004; Mitra et al., 2006; Simon et al., 2005; Yap et al., 2006; Czeh et al., 2007, Thomas et al., 2007; van Bokhoven et al., 2011).

A second approach highlights the functional role of adult neurogenesis in social processing and responding. Disrupting neurogenesis within the DG inhibits stress-induced social avoidance (LaGace et al., 2010), while disturbing SVZ proliferation impairs the detection and discrimination of opposite-sex odors (Feierstein et al., 2010). Likewise, ablating neurogenesis within the SVZ eliminates the ability of female mice to discriminate between mating partners and unfamiliar males (Oboti et al., 2011) as well as between dominant and subordinate mating 
candidates, with clear ramifications for reproductive success (Mak et al., 2007). Rather than emphasizing proliferative activity within the SVZ, Huang and Bittman (2002) explored the functional contributions of neo-neurogenesis in the OB. Three to seven weeks after BrdU treatment, adult male hamsters given access to an oestrus female had coexpression of BrdU and c-Fos in the OB, suggesting that newborn olfactory neurons are incorporated into sexual circuits. In a subsequent experiment, newborn cells in the main and accessory $\mathrm{OB}$, but not amygdala, medial preoptic area, or bed nucleus of the stria terminalis, were activated by sociosexual stimuli (Huang and Bittman, 2002). Colocalization of BrdU and c-Fos was observed after exposure to an oestrus female and female vaginal secretions, but activation was more widespread following exposure to an oestrus female. Collectively, these findings demonstrate that cues from multiple sensory modalities are required for the activation of adult-born OB neurons, and support a role for newborn olfactory neurons in socio-sexual processing.

\subsection{Gonadal Control of Adult Neurogenesis}

Social interactions are subserved by a host of neuro-hormonal processes which may mediate socially-induced changes in cell proliferation/survival. Interest in gonadal regulation of adult neurogenesis was initially piqued by reports of sex differences in hippocampal neurogenesis. Indeed, a growing body of research suggests that hippocampal cell proliferation is greater in females than males, and that this bias is tightly coupled to reproductive status. For example, female meadow voles show higher levels of hippocampal cell proliferation than adult males, with differences confined to the nonbreeding season (Galea and McEwen, 1999). Likewise, a female bias in hippocampal cell proliferation emerges when female rats enter proestrus (Tanapat et al., 1999). By contrast, cell survival favouring males has been documented in the hippocampus and anterior OB of adult rats (Tanapat et al., 1999; Peretto et al., 2001). Given that reproductively active meadow voles of both sexes have higher levels of cell survival than nonreproductively active animals, exposure to gonadal hormones may enhance cell survival in males and females alike (Ormerod and Galea, 2001; 2003). Collectively, those few studies that have explored cell proliferation/survival in both males and females suggest that adult neurogenesis is sexually dimorphic, with differences dictated, at least in part, by gonadal hormone exposure.

Estrogens can strikingly influence cell proliferation and survival, though effects vary with the sex and species of subject, as well as proliferative zone examined. Most work on estrogens and 
neurogenesis has been done with estradiol, a potent estrogen synthesized in the ovaries, adrenal glands, brain, and Leydig cells of the testis (Grodin et al., 1973; MacDonald et al., 1979; GarcieSegura et al., 1999). In line with the presence of estrogen receptor alpha and beta in the dentate hilus and GCL respectively (Blurton-Jones et al., 2004), the female bias in hippocampal cell proliferation may depend on estradiol, with suppressed proliferation seen immediately after ovariectomy (Tanapat et al., 1999). Further, the ability of estradiol to mediate neurogenesis appears to vary with sex. While estradiol stimulates hippocampal cell survival at all stages of cell maturation in females, effects in males are confined to the 'axon extension phase' (Ormerod et al., 2004). Estradiol also affects olfactory neurogenesis, though its influence may be modulated by social factors or other gonadal hormones, such as progesterone. Smith et al. (2001) observed an increase in SVZ and OB proliferation in oestrus prairie voles exposed to a male behind a mesh fence. In line with the presence of estrogen receptors in the SVZ (Fowler et al., 2005), this socially-induced surge in proliferation was not observed in ovariectomized females, and was rescued by estradiol treatment. Interestingly, estradiol administration in isolation does not exert an effect on SVZ proliferation (Hnatczuk et al., 1994). Taken together, results demonstrate that social interaction or opposite-sex chemosensory cues are required for estradiol to influence olfactory, but not hippocampal, neurogenesis.

The exact influence of progesterone on adult neurogenesis is not currently known, but mounting evidence suggests that its effects are limited, serving mainly to mediate the neurogenic effects of estradiol. While no research to date has addressed the impact of progesterone on olfactory neurogenesis, it has been shown to enhance cell proliferation in vitro (Wang et al., 2005). By contrast, estradiol-induced cell proliferation in the dentate gyrus of adult female rats is knocked down when high levels of estradiol are followed by elevations in progesterone (Tanapat et al., 2005; Galea et al., 2008). The independent effects of progesterone on neurogenesis have not been examined in females but, in males, progesterone does not appear to impact hippocampal cell proliferation (Zhang et al., 2010). Instead, and in contrast to the neurosuppressive effects observed in females, exogenous progesterone enhances cell survival and potentiates learning and memory in adult male mice (Zhang et al., 2010).

More research has addressed neurogenesis and androgens, such as testosterone and dihydrotestosterone, which are synthesized in the Leydig cells of the testis, brain, and adrenal cortex (Baulieu et al., 1977; Bon-Chu and Meng-Chun, 2002). Although androgen receptors are 
expressed by in vitro populations of SVZ-derived neural stem cells (Brannvall et al., 2005), the impact of androgens on olfactory neurogenesis is not presently known. By contrast, a substantial body of work indicates that androgens upregulate adult hippocampal neurogenesis. In male meadow voles, hippocampal neurogenesis is enhanced during the breeding season, when androgen levels are high. These effects appear to be specific to cell survival, as comparable levels of hippocampal cell proliferation are observed in reproductively active and inactive males (Ormerod and Galea, 2003). By the same token, castration suppresses cell survival in the hippocampus of adult male rats, with no notable effects on proliferation (Spritzer and Galea, 2005). Finally, chronic testosterone administration enhances cell survival in the hippocampus of castrated male rats (Spritzer and Galea, 2007), and HVC of female canaries (Rasika et al., 1994). Whether androgens exert their effects on hippocampal progenitors directly or indirectly via interaction with trophic factors is not presently known, but androgen-induced increases in cell survival appear to be conserved across sexes and species

\subsection{Neurogenesis in Noncanonical Neurogenic Regions}

Although most studies of adult neurogenesis have focused on the DG and SVZ/OB, there is accumulating evidence that SVZ-derived neuroblasts migrate to other brain regions. These include the piriform cortex (PCx; Bayer, 1986; Bernier et al., 2002; Shapiro et al., 2007a ; Klempin et al., 2011), neocortex (Dayer et al., 2005), amygdala (Bernier et al., 2002; Fowler et al., 2002), and striatum (Bedard et al., 2006). Indeed, neurons are added to the PCX and basolateral amygdala (BLA) at a rate that is concomitant with the production of OB neurons (Bernier et al., 2002). The PCx receives input from the OB and sends efferents to the hippocampus, thereby serving as a relay station for the two canonical neurogenic regions of the adult rodent brain. The survival and differentiation of new PCx neurons is up-regulated by olfactory enrichment (Shapiro et al., 2007b). Furthermore, the BLA has been shown to regulate hippocampal neurogenesis and fear-related activation of newborn neurons (Kirby et al., 2011). Collectively, these findings suggest that new neurons in the PCx and BLA contribute to the stability and plasticity of the limbic system, making them putative targets for social manipulations. 


\subsection{The Naked Mole-rat: A Eusocial Mammal}

The naked mole-rat (Heterocephalus glaber) is an ideal model system for studying the neurobiology of social behaviour. They exhibit the most striking example of eusociality among mammals and live in large subterranean colonies characterized by a rigid behavioural and reproductive hierarchy. Colonies typically range in size from 60 to 80 individuals where only a single dominant female (the queen) and one to three dominant males reproduce (Jarvis, 1981). All other colony members are socially subordinate and kept sexually suppressed through antagonism by the queen (Faulkes et al., 1990a). For males, reproductive suppression entails lower levels of urinary testosterone and plasma luteinizing hormone (LH) in subordinates than breeders, small testis, and blunted LH release in response to exogenous gonadotropin releasing hormone $(\mathrm{GnRh})$. While gametogenesis does occur in some subordinate males, rates are low and sperm are nonmotile (Faulkes et al., 1991; 1994, Faulkes and Abbott, 1991; Clarke and Faulkes, 1998; Zhou et al., 2013). For females, sexual repression is more pronounced, and ovulation is suppressed completely. In addition to an imperforate vagina and underdeveloped ovaries, subordinate females display lower levels of circulating testosterone, progesterone and LH, as well as a less profound LH response to GnRh than queens (Faulkes et al., 1990a; 1990b; 1991; Jarvis, 1991). By contrast, status differences in female estradiol levels have not been detected previously (Zhou et al., 2013). Whether this finding reflects extra-gonadal sources of estradiol, or sampling across the reproductive cycle remains to be determined.

Though less than $1 \%$ of subordinate naked mole-rats ever attain breeding status (Jarvis et al., 1994), subordinates that are removed from their natal colonies and paired with an opposite-sex conspecific will often become breeders and start their own colony. Within 5 to 8 days of pairing, females commence ovarian cyclicity and show a surge in circulating progesterone, while testosterone and LH levels are enhanced in males (Faulkes \& Abbott, 1993). Likewise, colonyhoused subordinates may become breeders if sexual suppression is lifted by a former breeder's death or removal (Margulis et al., 1995; Clarke and Faulkes, 1997). Though pronounced alterations in neural and endocrine functions accompany the change (Faulkes et al., 1990a; Margulis et al., 1995; Clarke and Faulkes, 1997; Seney et al., 2006; Holmes et al., 2008; Holmes et al., 2011; Mooney and Holmes, 2013), many or all subordinates are capable of transitioning to breeding status under the appropriate social conditions. This striking behavioural and 
physiological plasticity displayed by otherwise mature subordinates makes the naked mole-rat a prime candidate for the study of adult neurogenesis.

\subsection{The Present Study}

The present research examined the influence of social and gonadal variables on adult neurogenesis in the naked mole-rat. New neurons were identified and characterized using doublecortin (DCX) immunohistochemistry, a microtubule-associated protein expressed during periods of neuronal migration and differentiation. DCX was selected in order to avoid caveats associated with exogenous DNA synthesis markers such as BrdU and ${ }^{3} \mathrm{H}$-thymidine (E.g., toxicity/dose, blood-brain barrier permeability, double labeling for neuronal differentiation/survival). By comparing DCX expression in dominant breeding animals and subordinate non-breeding workers from intact colonies, I examined whether sex or social/reproductive status more profoundly impact adult neurogenic potential. Further, by evaluating doublecortin expression in subordinates that had been removed from their colony and paired with an opposite- or same-sex conspecific, I clarified the effects of social opportunity and social competition on adult neurogenesis. Lastly, in order to tease apart effects of gonadal activation and opposite-sex social/sensory cues, DCX expression was evaluated in intact and gonadectomized subordinates that had been housed with an opposite-sex conspecific. To accomplish this, naked mole-rats were sacrificed after a 6-month social manipulation, brains were collected, and tissue was processed for neurogenic activity in the DG, PCx, and BLA.

Given that neural regions found to be sexually dimorphic in other mammals are monomorphic in naked mole-rats (Peroulakis et al., 2002; Holmes et al., 2007), we predicted that previously characterized sex differences in neurogenesis would be reduced or absent. In addition, as behavioural and gonadal hormone profiles are more divergent for breeders and subordinates than male and female naked mole-rats, we hypothesized that DCX expression would vary with social status. In line with prior research demonstrating a neurogenic advantage for dominant versus subordinate individuals (Gould et al., 1997; 1998; Czeh et al., 2001; Van der Hart et al., 2002; Kozorovitskiy and Gould, 2004; Mitra et al., 2006; Simon et al., 2005; Yap et al., 2006; Czeh et al., 2007, Thomas et al., 2007; van Bokhoven et al., 2011), and reproductively active versus inactive animals (Ormerod and Galea, 2003), we predicted that breeding naked mole-rats would demonstrate higher DCX expression than subordinates. Finally, we expected that DCX 
expression would be enhanced in subordinates given the opportunity to transition status, and that this change would be contingent on intact gonadal function. Collectively, results clarify the relative impacts of social and gonadal factors on adult neurogenesis, and develop the naked mole rat as a model for testing the interplay between social behaviour and brain plasticity. 


\section{Chapter 1}

\section{Methods}

\subsection{Animals and Experimental Design}

Naked mole-rat colonies were maintained at the University of Toronto Mississauga in polycarbonate tubs (with Plexiglas ${ }^{\mathrm{TM}}$ lids) containing corncob bedding and connected by lengths of acrylic tubing. Animals were fed ad libitum on a diet consisting of sweet potato and $19 \%$ protein mash, and colonies were maintained on a 12:12 light/dark photoperiod in a temperature and humidity-controlled room $\left(28-30^{\circ} \mathrm{C} / 50 \% \mathrm{RH}\right)$. All animal procedures were approved by the University of Toronto Animal Care Committee and conducted in accordance with federal and institutional guidelines.

Naked mole-rats used in this study were also from a previous report (Mooney and Holmes, 2013). Subjects were dominant breeding adults between three and nine years of age, weighing 38 to $79 \mathrm{~g}$, and subordinate adults between two and three years of age, weighing 33 to $79 \mathrm{~g}$. As naked mole-rats typically reach adult body size within one year, can live for over 30 years in captivity, and do not show signs of aging well into their third decade (O'Riain and Jarvis, 1998; Buffenstein, 2005), the experimental animals were all young-aged adults. Subordinates were randomly assigned to four experimental groups: (1) Gonadally-intact and colony-housed (SUB; 6 male, 7 female), (2) gonadally-intact and pair-housed with a same-sex unfamiliar subordinate (SS; 6 male, 6 female), (3) gonadally-intact and pair-housed with an opposite-sex unfamiliar subordinate (OS; 7 male, 6 female), and (4) gonadectomized and pair-housed with an oppositesex unfamiliar subordinate (GDX; 7 male, 7 female). All Breeders ( $\mathrm{n}=9 ; 4$ male, 5 female) were gonadally-intact, and remained in their natal colonies for the duration of the experiment. Pairhoused animals were maintained in-colony prior to the experiment's initiation, at which time GDX animals were removed for surgery (see Mooney and Holmes, 2013) and allowed to recover. Then, all pair-housed animals were transferred to individual polycarbonate tubs with their appropriate cage mate and were maintained in their respective housing conditions for six months. 


\subsection{Histological Processing}

Animals were overdosed with avertin $(40 \mathrm{mg} / 100 \mathrm{~g})$ and brains were extracted, immersion fixed in $4 \%$ paraformaldehyde for $2 \mathrm{~h}$, then transferred to $30 \%$ sucrose in phosphate buffer for at least $24 \mathrm{~h}$. Thirty $\mu \mathrm{m}$ coronal slices in 4 series were taken using a freezing microtome and stored in cryoprotectant at $-20^{\circ} \mathrm{C}$. A one-in-four series from each animal was processed for DCX immunohistochemistry. Staining was done on free-floating sections pre-treated for antigen retrieval with sodium citrate buffer $\left(30 \mathrm{~min}\right.$ at $\left.80^{\circ} \mathrm{C}\right)$. Sections were quenched with $3 \% \mathrm{H}_{2} \mathrm{O}_{2}$ in PBS (30 min at RT) to inhibit endogenous peroxidase activity and blocked with PBS+ (3\% horse serum/0.3\% Triton-X 100/PBS; 30 min at RT). Tissue was incubated with goat monoclonal antiDCX antibody (1:200 in PBS+, $24 \mathrm{~h}$ at $4{ }^{\circ} \mathrm{C}$; Santa Cruz), followed by horse anti-goat biotynilated IgG (1:200 in PBS, $2 \mathrm{~h}$ at RT; Vector Laboratories). To visualize immunoreactive cells, an Avidin-Biotin complex incubation (2 $\mathrm{h}$ at RT; Vector Laboratories) and DAB reaction were performed. Sections were mounted on gelatin-subbed slides, counterstained with thionin and dehydrated with increasing concentrations of ethanol. Slides were cleared with xylene and cover-slipped.

\subsection{Quantification}

As the tissue used in this study was initially collected and processed in order to compare hypothalamic protein expression (Mooney and Holmes, 2013), anterior and posterior tissue was not available for all animals. Therefore, we were unable to quantify DCX expression in the SVZ/OB and ventral DG. DCX labeling was assessed throughout the rostrocaudal extent of the dorsal DG, PCx, and BLA. For the dorsal DG, DCX(+) cell bodies were counted in the hilus, subgranular zone (SGZ), and granule cell layer (GCL) (Figs 1 \& 2). For the PCx, the pattern of DCX label depended on cortical layer. No label was present in layer 1, DCX $(+)$ cell bodies were present in layer II, and scattered DCX(+) cell processes were seen in layer III (Fig 2). As a result, the number of $\mathrm{DCX}(+)$ cell bodies was counted in PCX layer II, while the number of DCX $(+)$ cell processes was counted in layer III. Due to dense DCX(+) label in the BLA for some animals (Fig 2), individual cells could not be reliably identified. Therefore, immunoreactivity in this region was quantified as total labeled surface area using Image J (NIH). Stereological assessment was not possible for the DG as the extent of usable tissue varied between subjects. To account for differences in tissue availability, the total number of $\operatorname{DCX}(+)$ cells within the dorsal 
DG was divided by the number of sections analyzed per animal, and a measure of mean DCX(+) cells per section was obtained. For the purpose of consistency, the same calculation was applied to the PCx and BLA.

\subsection{Data Analyses}

Two-way ANOVAs were used for statistical comparison of DCX expression within the dorsal DG, layers II and III of the PCx, and the BLA. Independent variables for each ANOVA included group (Breeders, SUB, SS, OS, and GDX) and sex. The a priori goals of this study were twofold: (1) to directly compare subordinates and breeders, and (2) to disentangle the effects of conspecific exposure and mating experience on subordinates removed from the colony. Therefore, differences between subordinates and breeders, as well as differences among pairhoused animals, were evaluated using Fisher's Least Significant Difference (LSD). The data are reported as mean $+/$ - SEM and results were considered significant if $p<0.05$. 


\section{Chapter 2}

\section{Results}

\subsection{Expression in the Dentate Gyrus}

DCX labeling in the DG revealed immature neurons predominately located in the SGZ (Fig 1). Main effects of group on DCX $(+)$ cells in the SGZ $(F(4,53)=2.714, \mathrm{p}=.039)$ and GCL $(F(4,53)=2.679, p=.042)$ were detected (Fig 3). In the SGZ, DCX labeling was lower for Breeders compared to all other groups (all ps $<0.05$ ) while only the breeder/subordinate difference was found in the GCL $(p<.05)$. No effect of group was observed in the hilus $(p>.05$; Fig 3) and no effects of sex or group x sex interactions were detected in any DG subregion.

\subsection{Expression in the Piriform Cortex}

A total of four animals were excluded from PCx and BLA analyses because of damage to the areas of interest.

Two-way ANOVA revealed a significant effect of group on the number of DCX(+) cells per section in PCx layer II $(F(4,49)=10.268, p<.0001$; Fig 4). Post-hoc comparisons indicated that the DCX labeling within this region was significantly lower for Breeders than all other groups $(p s<.05)$. SS-paired subordinates displayed fewer DCX $(+)$ cell per section than intact OS-paired and GDX OS-paired animals, whereas in-colony SUBs differed only from the intact OS group $(p s<.05)$. Post-hoc analyses did not reveal a significant difference between intact OS-paired subordinates and GDX OS-paired subordinates ( $p$ s > 0.05).

The significant effect of group extended to layer III of the PCx $(F(4,49)=6.899, p=.0002$; Fig 4). Post-hoc tests confirmed that Breeders showed fewer DCX(+) processes per section than SUB and OS groups, with SUB animals displaying lower DCX expression than SS and GDX group $(p s<.05)$. As with layer II, OS-paired animals showed greater DCX labeling than SSpaired individuals $(p<.05)$. Neither sex nor interaction effects were observed in layer II or III of the PCx. 


\subsection{Expression in the Basolateral Amygdala}

While a two-way ANOVA on DCX expression in the BLA did not reveal a significant effect of group, a significant group $\mathrm{x}$ sex interaction was observed $(F(4,49)=2.745, p=.039)$. When the data for females were analyzed independently, a significant effect of group emerged $(F(4,24)=$ 4.866, $p=.005$; Fig 5). Post-hoc comparisons revealed lower DCX expression for Breeders than SUB, as well as SS and GDX animals ( $p s<.05)$. Among out-of-colony groups, SS-paired animals displayed higher measures of DCX staining than the OS group $(p<.05)$. Among males, no group differences were observed ( $p s>.05$; Fig 5). 


\section{Chapter 3}

\section{Discussion}

\subsection{Summary}

Our results demonstrate that breeding naked mole-rats have significantly fewer immature $(\mathrm{DCX}+)$ neurons in the DG and PCx compared to socially subordinate individuals. Breeders also had fewer DCX + cells than subordinates that were removed from their colonies and paired for a six-month period. Although this effect of status extended to the BLA, it was only seen in females, with colony-housed subordinate females displaying more DCX labeling than queens. Among paired groups, the effects of same- versus opposite-sex housing were region-specific. Though no effect of housing condition was observed in the dorsal DG, DCX immunoreactivity in the PCx was higher for opposite- than same-sex pair-housed subordinates, with the opposite pattern observed in the BLA. DCX expression was comparable in intact and GDX opposite-sex paired animals, speaking to a larger role for social than gonadal factors in control of adult neurogenesis. Additional work will clarify whether group differences represent socially induced alterations in cell proliferation or neuronal differentiation/survival.

\subsection{Adult Neurogenesis and Social Factors}

The finding that subordinate naked mole-rats have more new neurons than breeders contrasts previous reports on neurogenesis and social rank. In fish, birds, tree shrews, primates, and traditional laboratory rodents, subordinate individuals have reduced cell proliferation and/or neurogenesis in the hippocampus (Gould et al., 1997; 1998; Yap et al., 2006 Czeh et al., 2001; 2002; van der Hart et al., 2002; Kozorovitskiy and Gould, 2004; Pravosudov et al., 2005; Simon et al., 2005; Czeh et al., 2007; Thomas et al., 2007; Van Bokhoven et al., 2011; Maruska et al., 2012). Though extrahippocampal neurogenesis has received considerably less attention, what few studies have been done report that status-associated differences are not observed in the BLA (Mitra et al., 2006) or SVZ (Czeh et al., 2007). It has been suggested that stress induced by contact with dominant conspecifics, and concomitant elevations in circulating glucocorticoids (GCs), suppress subordinate neurogenesis across vertebrates, resulting in behavioural inhibition (Thomas et al., 2007; Lehmann et al., 2013). 
The present results suggest that this relationship may not hold for the naked mole-rat. Unfortunately, we did not measure the stress response in these animals. Previous studies on social status and the stress system in this species have yielded inconsistent results, with subordinates having higher cortisol in one study (Clarke and Faulkes, 1997) but not in others (Clarke and Faulkes, 1998; Clarke and Faulkes, 2001). Moreover, instead of displaying the depressive-like behavioural profile typically associated with chronic stress and low levels of neurogenesis (Gould et al., 1997; Fuchs and Flügge, 2002; Thomas et al., 2007; Liu et al., 2008; Taliaz et al., 2009; Snyder et al., 2011; Pinheiro et al., 2013), subordinate naked mole-rats are highly active, participating in burrowing, foraging, colony defense, and pup care (Sherman et al., 1991). These departures from the typical dominant/subordinate dynamic are not necessarily surprising. Naked mole-rat social organization, comprised of relatively stable hierarchies maintained by reassertions of status from dominant individuals as well as potential subordinate coping outlets (e.g., close proximity to kin), differs from the artificial dominance hierarchies and winner-loser couplings that have been highlighted in prior neurogenesis research. The status system and social organization of the naked mole-rat more closely resembles that of other cooperatively breeding species, in which dominant individuals have equivalent or higher basal GCs than subordinates (Creel, 2001). In addition to a potential role for GCs, elevated oxytocin production or output in subordinates (Mooney and Holmes, 2013) may stimulate neuronal growth, protecting against the suppressive effects of stress on hippocampal plasticity (Leuner et al., 2012). If GC levels truly do differ between dominant and subordinate naked mole-rats, our results may reflect a biphasic effect of stress on naked mole-rat neurobiology (Joels, 2006; 2007). In short, mild and/or predictable stress (as experienced by subordinate individuals periodically exposed to breeder aggression) may serve to stimulate adult neurogenesis (E.g., Parihar et al., 2009; Lyons et al., 2010), while severe and chronic stress (as experienced by breeders inciting aggression to maintain dominance) may suppress it. Alternatively, if basal GCs do not vary with status, the present results may stem from status-related differences in GC responsiveness. Accumulating evidence suggests that hippocampal neurogenesis regulates stress reactivity at endocrine and behavioural levels, with reduced neurogenesis in the adult DG linked to stress-induced GC hypersecretion and depressive-like behaviour in mice (Snyder et al., 2011), as well as high GC responsiveness and cognitive/behavioural inflexibility in fish (Moreira et al., 2004; Ruis-Gomez et al., 2011; Johansen et al., 2012). Future studies should determine whether 
this pattern extends to the naked mole-rat, and clarify the relationship between status and the stress system in this species.

In addition to status-related stress, the neurogenic capacity of breeding and subordinate naked mole-rats may reflect differing levels of behavioural plasticity. While subordinate naked molerats retain the ability to transition social status throughout life, the switch to breeding status does not appear to be reversible, with breeders typically retaining their status until death (Jarvis, 1991; Buffenstein, 2005). In addition, subordinate naked mole-rats respond flexibly to conspecifics, tailoring their behaviour to the relative status of their interaction partner and displaying avoidance/accommodation during encounters with high ranking animals versus assertive behaviour when faced with animals of lower status. Behavioural responding in dominant animals is comparatively rigid, with dominance or aggressive behaviours expressed in the majority of social encounters. Indeed, queens and breeding males display more pass-over behaviour than subordinates and initiate the vast majority of shoving in-colony (Clarke and Faulkes, 1997; 1998; 2001). As subordinates must continually navigate and respond appropriately to the changing social hierarchy, it is possible that social memory demands are greater for subordinates than breeders, necessitating a higher capacity for learning and memory formation, faster extinction of old memories, and an enhanced ability to detect and internalize cues conveying the sex, status, and health of conspecifics. Adult-born neurons have been tied to each of these functions (Saxe et al., 2006; Mak et al., 2007; Deng et al., 2009; Feierstein et al., 2010; Leuner and Gold, 2010; Noonan et al., 2010; Pan et al., 2013) as well as social recognition processes (Mak and Weiss, 2010; Oboti et al., 2011), and so may serve to meet the greater social memory demands faced by subordinate naked mole-rats.

As behavioural and neural plasticity is greater in juvenile than adult members of diverse vertebrate species, the high neurogenic potential of subordinate naked mole-rats may also be a reflection of life stage. Subordinate naked mole-rats are reproductively quiescent and remarkably monomorphic (Faulkes et al., 1990a; 1991; Jarvis, 1991), and subordinates display a prepubertal phenotype regardless of age. Given that studies on humans, nonhuman primates, and other rodent species have demonstrated dramatic declines in neurogenesis between the juvenile period and adulthood (Gould et al., 1999; Barker et al., 2005; McDonald and Wojtowicz, 2005; Ben Abdallah et al., 2010; Knoth et al., 2010), the greater neurogenic potential of subordinate naked mole-rats may reflect life stage rather than status, per se. Alternatively, as breeders in the present 
study were older on average than subordinates, the status differences observed may be a function of age. Though a regression of age on DCX expression within breeders was not significant, future studies should clarify whether low neurogenesis among breeders can be attributed to declines in neurogenesis with advancing age (Kuhn et al., 1996; Kempermann et al., 1998; Gould et al., 1999; Enwere et al., 2004; Barker et al., 2005; McDonald and Wojtowicz, 2005; Rao et al., 2005; Olariu et al., 2007; Ben Abdallah et al., 2010; Knoth et al., 2010), impaired negative feedback control of GCs (Sapolsky et al., 2002), or an age-related increase in neurogenic vulnerability to psychosocial stress (Simon et al., 2005).

While breeder-subordinate differences in neurogenesis were seen in multiple brain regions, the effect of housing condition on the subordinate brain was region-specific. In line with prior research indicating that social factors, such as mating experience and opposite-sex chemosensory cues affect olfactory neurogenesis in adulthood (Smith et al., 2001; Baudoin et al., 2005; Mak et al., 2007; Larsen et al., 2008; Oboti et al., 2009; Corona et al., 2011), DCX expression in layer II of the PCx was highest in subordinates that were removed from their natal colonies and paired with an unfamiliar, opposite-sex conspecific. This is the first study to date to examine the relative contributions of mating experience and opposite-sex social/chemosensory stimulation to neurogenesis in the PCx; our results suggest that neurogenesis in this region is predominantly regulated by chemosensory exposure. By contrast, the effects of mating experience, gestation, parenthood, and status-associated fluctuations in gonadal hormones appear to be negligible, as DCX expression did not differ for intact and GDX opposite-sex paired animals.

DCX expression within the BLA was noteworthy in that this was the only brain area to show a sexually dimorphic pattern of staining. Group differences among subordinates were confined to females, with same-sex paired individuals showing higher levels of neurogenesis than oppositesex paired animals. It is interesting to note that the reverse pattern of staining was observed in layer II of the PCx, suggesting that different aspects of social interaction promote neural plasticity in these areas. Given the role of the BLA in fear conditioning and inhibitory avoidance (Maren et al., 1996a; Maren et al., 1996b; Cousens and Otto, 1998; Maren, 1998; Wilensky et al., 2000), it may be that neurogenesis in this region is stimulated by behavioural or chemosensory cues conveying high status and/or social threat. As female, but not male, naked mole-rats compete for dominant status in the absence of the queen (Clarke and Faulkes,1997; 1998), aggressive competition and the continuous threat of harm may have contributed to the high levels 
of DCX expression seen for same-sex paired females. A role for BLA neurogenesis in danger appraisal is consistent with the higher levels of DCX expression observed for subordinate colony members, which are exposed to chronic antagonism by the queen.

\subsection{Adult Neurogenesis and Gonadal Factors}

Results suggest that previously characterized effects of gonadal hormones on adult neurogenesis are reduced or absent in the naked mole-rat. While the low neurogenic capacity observed in breeding females lines up with research demonstrating that queens have higher levels of circulating progesterone than same-sex subordinates (Zhou et al., 2013), low DCX expression did not extend to females given the opportunity to transition status. Both groups were exposed to an environment conducive to reproductive activation, yet neurogenesis was higher in the DG and PCX of intact opposite-sex pair housed females compared to queens. Furthermore, DCX expression was comparable among intact and GDX opposite-sex pair housed subordinates. The apparent independence of adult neurogenesis from gonadal factors in this species is intriguing, and corresponds with prior reports that status related changes in naked mole-rat brain morphology are not reversed by long-term gonadectomy (Holmes et al., 2011). Findings also line up with research demonstrating that the impact of gonadal status on hippocampal neurogenesis is dictated by the duration of time a rodent has been deprived of normal circulating levels of gonadal hormones. As ovariectomy in traditional laboratory rodents suppresses hippocampal cell proliferation in the short- (Tanapat et al., 1999), but not long-term (Tanapet et al., 2005; LaGace et al., 2007), it is possible that ovariectomised rats and reproductively suppressed naked molerats maintain high levels of hippocampal neurogenesis via compensatory mechanisms, such as extra-gonadal estrogen production. This possibility is supported by reports of adrenal estradiol synthesis in female naked mole-rats, and comparable concentrations of plasma estradiol among intact breeders, GDX breeders, and subordinates (Zhou et al., 2013). While it may be that estrogen mediates socially induced changes in SVZ-derived neurogenesis (Smith et al., 2001), it is also possible that extra-gonadal hormones such as prolactin regulate neurogenesis in the PCx and BLA (Mak et al., 2007). Future work will clarify whether our failure to detect an influence of gonadal factors on adult neurogenesis reflects extra-gonadal sources of regulatory hormones or hormonal insensitivity. 


\subsection{Conclusion}

Collectively, these data show a striking effect for social, but not gonadal, status on the regulation of neurogenesis in the eusocial mammalian brain. While the origin, maturation time, and ultimate fate of adult-born cells in naked mole-rats is not yet known, it is clear that neurogenesis in this species is highly sensitive to the social environment. Given the observed effects of social experience on neurogenesis, and the remarkable behavioural diversity and plasticity exhibited by this species, the naked mole-rat will help us understand the relationship between adult neural plasticity and social behaviour in mammals. 


\section{References}

Altman, J (1963), Autoradiographic investigation of cell proliferation in the brains of rats and cats. Anatomical Rec, 145(4): 573-591.

Altman, J (1969), Autoradiographic and histological studies of postnatal neurogenesis. III. Dating the time of production and onset of differentiation of cerebellar microneurons in rats. Journal Comp Neurol, 136(3): 269-293.

Altman, J, Das, GD (1965a), Post-natal origin of microneurones in the rat brain. Nature, 207(5000): 953.

Altman, J, Das, GD (1965b), Autoradiographic and histological evidence of postnatal hippocampal neurogenesis in rats. J Comparative Neurol, 124(3): 319-335.

Barker, JM, Wojtowicz, JM, Boonstra, R (2005), Where's my dinner? Adult neurogenesis in free-living food-storing rodents. Genes Brain Behav 4(2): 89-98.

Baulieu, EE (1996), Neurosteroids: of the nervous system, by the nervous system, for the nervous system. Recent Prog Hormone Res, 52: 1-32.

Baudoin, C, Busquet, N, Dobson, FS, Gheusi, G, Féron, C, Durand, JL., ..., Todrank, J (2005): Male-female associations and female olfactory neurogenesis with pair bonding in Mus spicilegus. Biol J.Lin Soc 84(3): 323-334.

Bayer, SA (1986), Neurogenesis in the rat primary olfactory cortex. Int J Dev Neurosci 4(3): 251-271.

Bedard, A, Gravel, C, Parent, A (2006), Chemical characterization of newly generated neurons in the striatum of adult primates. Exp Brain Res 170(4): 501-512.

Ben Abdallah, NMB, Slomianka, L, Vyssotski, AL, Lipp, HP (2010), Early age-related changes in adult hippocampal neurogenesis in C57 mice. Neurobiol Aging 31(1): 151-161. 
Bernier, PJ, Bédard, A, Vinet, J, Lévesque, M, Parent, A (2002), Newly generated neurons in the amygdala and adjoining cortex of adult primates. Proc Natl Acad Sci U S A 99(17): 11464-11469.

Blurton-Jones, M, Kuan, PN, Tuszynski, MH (2004), Anatomical evidence for transsynaptic influences of estrogen on brain-derived neurotrophic factor expression. J Comp Neurol, 468(3): 347-360.

Bon-chu, C, Meng-Chun, H (2002). Androgen biosynthesis and degradation. In Androgens and Androgen Receptor (pp. 1-15). Springer US.

Brännvall, K., Bogdanovic, N., Korhonen, L., Lindholm, D (2005), 19-Nortestosterone influences neural stem cell proliferation and neurogenesis in the rat brain. European $J$ Neurosci, 21(4): 871-878.

Buffenstein R (2005), The naked mole-rat: a new long-living model for human aging research. $J$ Gerontol A Biol Sci Med Sci 60: 1369-1377.

Chiasson, BJ, Tropepe, V, Morshead, CM, van der Kooy, D (1999), Adult mammalian forebrain ependymal and subependymal cells demonstrate proliferative potential, but only subependymal cells have neural stem cell characteristics. J Neurosci, 19(11): 4462-4471.

Clarke, FM, Faulkes, CG (1997), Dominance and queen succession in captive colonies of the eusocial naked mole-rat, Heterocephalus glaber. Proc R Soc B,264(1384): 993-1000.

Clarke FM, Faulkes CG (1998), Hormonal and behavioural correlates of male dominance and reproductive status in captive colonies of the naked mole-rat, Heterocephalus glaber. Proc Biol Sci 265:1391-1399

Clarke, FM, Faulkes, CG (2001), Intracolony aggression in the eusocial naked mole-rat, $<\mathrm{i}>$ Heterocephalus glaber</i>. Anim Behav 61(2): 311-324.

Corona, R, Larriva-Sahd, J, Paredes, RG (2011), Paced-mating increases the number of adult new born cells in the internal cellular (granular) layer of the accessory olfactory bulb. PloS one, 6(5): e19380. 
Cousens, G, Otto, T (1998), Both pre-and posttraining excitotoxic lesions of the basolateral amygdala abolish the expression of olfactory and contextual fear conditioning. Behav Neurosci 112(5): 1092.

Creel, S (2001), Social dominance and stress hormones. Trends Ecol Evol 16(9): 491-497.

Cushing, BS, Wynne-Edwards, KE (2006), Estrogen receptor- $\alpha$ distribution in male rodents is associated with social organization. J Compar Neurol, 494(4), 595-605.

Czéh, B, Michaelis, T, Watanabe, T, Frahm, J, de Biurrun, G, van Kampen, M, ... Fuchs, E (2001), Stress-induced changes in cerebral metabolites, hippocampal volume, and cell proliferation are prevented by antidepressant treatment with tianeptine. Proc Natl Acad Sci U S A 98(22): 12796-12801.

Czéh, B, Müller-Keuker, JI, Rygula, R, Abumaria, N, Hiemke, C, Domenici, E, Fuchs, E (2007), Chronic social stress inhibits cell proliferation in the adult medial prefrontal cortex: hemispheric asymmetry and reversal by fluoxetine treatment. Neuropsychopharmacol 32(7): 1490-1503.

Dayer, AG, Cleaver, KM, Abouantoun, T, Cameron, HA (2005), New GABAergic interneurons in the adult neocortex and striatum are generated from different precursors. $J$ Cell Biol, 168(3): 415-427.

Deng, W, Saxe, MD, Gallina, IS, Gage, FH (2009), Adult-born hippocampal dentate granule cells undergoing maturation modulate learning and memory in the brain. J Neurosci 29(43): 13532-13542.

Doetsch, F, García-Verdugo, JM, Alvarez-Buylla, A (1997), Cellular composition and threedimensional organization of the subventricular germinal zone in the adult mammalian brain. J Neurosci, 17(13): 5046-5061.

Enwere, E, Shingo, T, Gregg, C, Fujikawa, H, Ohta, S, Weiss, S (2004), Aging results in reduced epidermal growth factor receptor signaling, diminished olfactory neurogenesis, and deficits in fine olfactory discrimination. $J$ Neurosci 24(38): 8354-8365. 
Faulkes, CG, Abbott, DH, Jarvis, JUM (1990a), Social suppression of ovarian cyclicity in captive and wild colonies of naked mole-rats, Heterocephalus glaber. J Reprod Fertil 88(2): 559-568.

Faulkes, CG, Abbott, DH, Jarvis, JUM, Sherriff, FE (1990b), LH responses of female naked mole-rats, Heterocephalus glaber, to single and multiple doses of exogenous GnRH. $J$ Reproduc and fertility, 89(1): 317-323.

Faulkes, CG, Abbott, DH, Jarvis, JUM (1991), Social suppression of reproduction in male naked mole-rats, Heterocephalus glaber. J Reprod Fertil 91(2): 593-604.

Faulkes, CG, Abbott, DH (1991), Social control of reproduction in breeding and non-breeding male naked mole-rats (Heterocephalus glaber).J Repro Fertil, 93(2): 427-435.

Faulkes, CG, Abbott, DH (1993), Evidence that primer pheromones do not cause social suppression of reproduction in male and female naked mole-rats (Heterocephalus glaber). J Repro Fertil, 99(1): 225-230.

Faulkes, CG, Trowell, SN, Jarvis, JUM, Bennett, NC (1994), Investigation of numbers and motility of spermatozoa in reproductively active and socially suppressed males of two eusocial African mole-rats, the naked mole-rat (Heterocephalus glaber) and the Damaraland mole-rat (Cryptomys damarensis). J Repro Fertil, 100(2): 411-416.

Feierstein, CE, Lazarini, F, Wagner, S, Gabellec, MM, De Chaumont, F, Olivo-Marin, JC, ... Gheusi, G (2010), Disruption of adult neurogenesis in the olfactory bulb affects social interaction but not maternal behaviour. Front Behav Neurosci 4.

Flanagan-Cato, LM, Calizo, LH, Griffin, GD, Lee, BJ, Whisner, SY (2006), Sexual Behaviour Induces the Expression of Activity-Regulated Cytoskeletal Protein and Modifies Neuronal Morphology in the Female Rat Ventromedial Hypothalamus. $J$ Neuroendocrinol, 18(11): 857-864.

Fowler, CD, Liu, Y, Ouimet, C, Wang, Z (2002), The effects of social environment on adult neurogenesis in the female prairie vole. J Neurobiol, 51(2): 115-128. 
Fowler CD, Johnson F, Wang Z. 2005. Estrogen regulation of cell proliferation and distribution of estrogen receptor alpha in the brains of adult female prairie and meadow voles. J Comp Neurol 489: 166-179.

Fuchs, E, Flügge, G (2002), Social stress in tree shrews: effects on physiology, brain function, and behaviour of subordinate individuals. Pharmacol Biochem and Behav 73(1): 247258.

Galea, LA (2008), Gonadal hormone modulation of neurogenesis in the dentate gyrus of adult male and female rodents. Brain Res Rev, 57(2): 332-341.

Galea, LAM, McEwen, BS (1999), Sex and seasonal changes in the rate of cell proliferation in the dentate gyrus of adult wild meadow voles. Neurosci, 89(3), 955-964.

Garcia-Segura, LM, Wozniak, A, Azcoitia, I, Rodriguez, JR, Hutchison, RE, Hutchison, JB (1999), Aromatase expression by astrocytes after brain injury: implications for local estrogen formation in brain repair. Neurosci,89(2): 567-578.

Goldman, SA, Nottebohm, F (1983), Neuronal production, migration, and differentiation in a vocal control nucleus of the adult female canary brain. P Natl Acad Sci U S A, 80(8): 2390-2394.

Gould, E, McEwen, BS, Tanapat, P, Galea, LA, Fuchs, E (1997), Neurogenesis in the dentate gyrus of the adult tree shrew is regulated by psychosocial stress and NMDA receptor activation. $J$ Neurosci, 17(7): 2492-2498.

Gould, E, Reeves, AJ, Fallah, M, Tanapat, P, Gross, CG, Fuchs, E (1999), Hippocampal neurogenesis in adult Old World primates. Proc Natl Acad Sci U S A 96(9): 5263-5267.

Gould, E, Tanapat, P, McEwen, BS, Flügge, G, Fuchs, E (1998), Proliferation of granule cell precursors in the dentate gyrus of adult monkeys is diminished by stress. Proc Natl Acad Sci U S A 95(6): 3168-3171.

Grodin JM, Siiteri PK, MacDonald PC (1973), Source of estrogen production in postmenopausal women. J Clin Endocrinol Metab 36: 207-214. 
Holmes, MM, Rosen, GJ, Jordan, CL, de Vries, GJ, Goldman, BD, Forger, NG (2007), Social control of brain morphology in a eusocial mammal.Proc Natl Acad Sci U S A, 104(25): 10548-10552.

Holmes, MM, Goldman, BD, Forger, NG (2008), Social status and sex independently influence androgen receptor expression in the eusocial naked mole-rat brain. Horm Behav 54(2): 278-285.

Holmes, MM, Seney, ML, Goldman, BD, Forger, NG (2011), Social and hormonal triggers of neural plasticity in naked mole-rats. Behav Brain Res 218(1): 234-239.

Hnatczuk, OC, Lisciotto, CA, DonCarlos, LL, Carter, CS, Morrell, JI (1994), Estrogen receptor immunoreactivity in specific brain areas of the prairie vole (Microtus ochrogaster) is altered by sexual receptivity and genetic sex. J Neuroendocrinol, 6(1): 89-100.

Huang, L, Bittman, EL (2002), Olfactory bulb cells generated in adult male golden hamsters are specifically activated by exposure to estrous females. Horm Behav, 41(3): 343-350.

Jarvis, JU (1981), Eusociality in a mammal: cooperative breeding in naked mole-rat colonies. Science, 212(4494): 571-573.

Jarvis, JU. (1991). Reproduction of naked mole-rats. The biology of the naked mole-rat, 384 .

Jarvis, JU, O'Riain, MJ., Bennett, NC, Sherman, PW (1994), Mammalian eusociality: a family affair. Trends Ecol Evol 9(2): 47-51.

Joëls, M (2006), Corticosteroid effects in the brain: U-shape it. Trends Pharmacol Sci 27(5): 244-250.

Joëls, M (2007), Role of corticosteroid hormones in the dentate gyrus. Prog Brain Res 163: 355370.

Johansen, IB, Sørensen, C, Sandvik, GK, Nilsson, GE, Höglund, E, Bakken, M, Øverli, Ø (2012), Neural plasticity is affected by stress and heritable variation in stress coping style. Comp Biochem Phys D 7(2): 161-171. 
Kempermann, G, Kuhn, HG, Gage, FH (1998), Experience-induced neurogenesis in the senescent dentate gyrus. J Neurosci 18(9): 3206-3212.

Kerr, JE, Allore, RJ, Beck, SG, Handa, RJ (1995), Distribution and hormonal regulation of androgen receptor (AR) and $\mathrm{AR}$ messenger ribonucleic acid in the rat hippocampus. Endocrinol, 136(8): 3213-3221.

Kirby, ED, Friedman, AR, Covarrubias, D, Ying, C, Sun, WG, Goosens, KA, ... Kaufer, D (2011), Basolateral amygdala regulation of adult hippocampal neurogenesis and fearrelated activation of newborn neurons. Molec Psychiatr 17(5): 527-536.

Klempin, F, Kronenberg, G, Cheung, G, Kettenmann, H, Kempermann, G (2011), Properties of doublecortin-(DCX)-expressing cells in the piriform cortex compared to the neurogenic dentate gyrus of adult mice. PloS one 6(10): e25760.

Kozorovitskiy, Y, Gould, E (2004), Dominance hierarchy influences adult neurogenesis in the dentate gyrus. J Neurosci 24(30): 6755-6759.

Knoth, R, Singec, I, Ditter, M, Pantazis, G, Capetian, P, Meyer, RP, ... Kempermann, G (2010), Murine features of neurogenesis in the human hippocampus across the lifespan from 0 to 100 years. PloS one, 5(1): e8809.

Kuhn, HG, Dickinson-Anson, H, Gage, FH (1996), Neurogenesis in the dentate gyrus of the adult rat: age-related decrease of neuronal progenitor proliferation. J Neurosci 16(6): 2027-2033.

Lagace, DC, Donovan, MH, DeCarolis, NA, Farnbauch, LA, Malhotra, S, Berton, O, ... Eisch, AJ (2010), Adult hippocampal neurogenesis is functionally important for stress-induced social avoidance. Proc Natl Acad Sci U S A 107(9): 4436-4441.

Lagace, D. C., Fischer, S. J., \& Eisch, A. J. (2007). Gender and endogenous levels of estradiol do not influence adult hippocampal neurogenesis in mice.Hippocampus, 17(3): 175-180.

Larsen, CM, Kokay, IC, Grattan, DR (2008), Male pheromones initiate prolactin-induced neurogenesis and advance maternal behaviour in female mice. Horm Behav, 53(4): 509517. 
Lehmann, ML, Brachman, RA, Martinowich, K, Schloesser, RJ, Herkenham, M (2013), Glucocorticoids orchestrate divergent effects on mood through adult neurogenesis. $J$ Neurosci 33(7): 2961-2972.

Leuner, B, Glasper, ER, Gould, E (2010), Sexual experience promotes adult neurogenesis in the hippocampus despite an initial elevation in stress hormones. PLoS One 5(7): e11597.

Leuner, B, Gould, E (2010), Structural plasticity and hippocampal function. Annu Rev Psychol 61: 111.

Leuner, B, Caponiti, JM, Gould, E (2012), Oxytocin stimulates adult neurogenesis even under conditions of stress and elevated glucocorticoids. Hippocampus, 22(4): 861-868.

Lieberwirth, C, Wang, Z (2012), The social environment and neurogenesis in the adult mammalian brain. Front Hum Neurosci 6: 118.

Liu, Q, Yu, J, Mao-Ying, QL, Mi, WL, Li, B, Wang, YQ, ... Wu, GC (2008), Repeated clomipramine treatment reversed the inhibition of cell proliferation in adult hippocampus induced by chronic unpredictable stress. Pharmacogenomics $J$ 8(6): 375-383.

Lyons, DM, Buckmaster, PS, Lee, A. G, Wu, C, Mitra, R, Duffey, LM, ... Schatzberg, AF (2010), Stress coping stimulates hippocampal neurogenesis in adult monkeys. Proc Natl Acad Sci U S A 107(33): 14823-14827.

MacDonald PC, Madden JD, Brenner PF, Wilson JD, Siiteri PK. (1979), Origin of estrogen in normal men and in women with testicular feminization. J Clin Endocrinol Metab 49:905-916.

Magavi SSP, Mitchell BD, Szentirmai O, Carter BS, Macklis JD (2005), Adult-born and preexisting olfactory granule neurons undergo distinct experience-dependent modifications of their olfactory responses in vivo. J. Neurosci 25(46): 10729-10739.

Mak, GK, Enwere, EK, Gregg, C, Pakarainen, T, Poutanen, M, Huhtaniemi, I, Weiss, S (2007), Male pheromone-stimulated neurogenesis in the adult female brain: possible role in mating behaviour. Nat Neurosci 10(8): 1003-1011. 
Mak, GK, Weiss, S (2010), Paternal recognition of adult offspring mediated by newly generated CNS neurons. Nat Neurosci 13(6): 753-758.

Maren, S (1998), Overtraining does not mitigate contextual fear conditioning deficits produced by neurotoxic lesions of the basolateral amygdala. J Neurosci 18(8): 3088-3097.

Maren, S, Aharonov, G, Fanselow, MS (1996a), Retrograde abolition of conditional fear after excitotoxic lesions in the basolateral amygdala of rats: absence of a temporal gradient. Behav Neurosci 110(4): 718.

Maren, S, Aharonov, G, Stote, DL, Fanselow, MS (1996b), N-methyl-D-aspartate receptors in the basolateral amygdala are required for both acquisition and expression of conditional fear in rats. Behav Neurosci 110(6): 1365.

Margulis, SW, Saltzman, W, Abbott, DH (1995), Behavioural and hormonal changes in female naked mole-rats (Heterocephalus glaber) following removal of the breeding female from a colony. Horm Behav 29(2): 227-247.

Maruska, KP, Carpenter, RE, Fernald, RD (2012), Characterization of cell proliferation throughout the brain of the African cichlid fish Astatotilapia burtoni and its regulation by social status. J Comp Neurol 520(15): 3471-3491.

Matsuoka, M, Yoshida-Matsuoka, J, Sugiura, H, Yamagata, K, Ichikawa, M, Norita, M (2002). Mating behaviour induces differential Arc expression in the main and accessory olfactory bulbs of adult rats. Neurosci Lett, 335(2): 111-114.

McDonald, HY, Wojtowicz, JM (2005), Dynamics of neurogenesis in the dentate gyrus of adult rats. Neurosci Lett 385(1): 70-75.

Ming, GL, Song, H (2005), Adult neurogenesis in the mammalian central nervous system. Annu. Rev. Neurosci., 28: 223-250.

Mitra, R, Sundlass, K, Parker, KJ, Schatzberg, AF, Lyons, DM (2006), Social stress-related behaviour affects hippocampal cell proliferation in mice. Physiol Behav 89(2): 123-127. 
Mooney, SJ, Holmes, MM (2013), Social condition and oxytocin neuron number in the hypothalamus of naked mole-rats $(<\mathrm{i}>$ Heterocephalus glaber $</ \mathrm{i}>)$. Neurosci 232(1): 151-160.

Moreira, PSA, Pulman, KGT, Pottinger, TG (2004), Extinction of a conditioned response in rainbow trout selected for high or low responsiveness to stress. Horm Behav 46(4): 450457.

Nissant A, Bardy C, Katagiri H, Murray K, Lledo P-M (2009), Adult neurogenesis promotes synaptic plasticity in the olfactory bulb. Nat Neurosci 12: 728-730.

Noonan, MA, Bulin, SE, Fuller, DC, Eisch, AJ (2010), Reduction of adult hippocampal neurogenesis confers vulnerability in an animal model of cocaine addiction. $J$ Neurosci 30(1): 304-315.

Oboti, L, Schellino, R, Giachino, C, Chamero, P, Pyrski, M, Leinders-Zufall, T, ... Peretto, P (2011), Newborn interneurons in the accessory olfactory bulb promote mate recognition in female mice. Front Neurosci, 5: 113.

Oboti, L, Savalli, G, Giachino, C, De Marchis, S, Panzica, GC, Fasolo, A, Peretto, P (2009), Integration and sensory experience-dependent survival of newly-generated neurons in the accessory olfactory bulb of female mice. Eur J Neurosci 29(4): 679-692.

Olariu, A, Cleaver, KM, Cameron, HA (2007), Decreased neurogenesis in aged rats results from loss of granule cell precursors without lengthening of the cell cycle. J Comp Neurol 501(4): 659-667.

O’Riain MJ, Jarvis JU (1998), The dynamics of growth in naked mole-rats: the effects of litter order and changes in social structure. J Zool 246:49-60.

Ormerod, B. K., \& Galea, L. A. M. (2001). Reproductive status influences cell proliferation and cell survival in the dentate gyrus of adult female meadow voles: a possible regulatory role for estradiol. Neuroscience, 102(2), 369-379 
Ormerod, B. K., \& Galea, L. A. M. (2003). Reproductive status influences the survival of new cells in the dentate gyrus of adult male meadow voles.Neuroscience letters, 346(1), 25 28.

Ormerod, BK, Lee, T, Galea, LAM (2003), Estradiol initially enhances but subsequently suppresses (via adrenal steroids) granule cell proliferation in the dentate gyrus of adult female rats. J Neurobiol, 55(2): 247-260.

Ormerod, BK, Lee, TY, \& Galea, LAM (2004), Estradiol enhances neurogenesis in the dentate gyri of adult male meadow voles by increasing the survival of young granule neurons. Neurosci, 128(3): 645-654.

Pan, YW, Storm, DR, Xia, Z (2013), Role of Adult Neurogenesis in Hippocampus-Dependent Memory, Contextual Fear Extinction and Remote Contextual Memory: New Insights from ERK5 MAP Kinase. Neurobiol Learn Mem 105: 81-92.

Parihar, VK, Hattiangady, B, Kuruba, R, Shuai, B, Shetty, AK (2009), Predictable chronic mild stress improves mood, hippocampal neurogenesis and memory. Molec Psychiatr 16(2): 171-183.

Paton JA, Nottebohm F (1984), Neurons generated in adult brain are recruited into functional circuits. Science 225: 1046-1048.

Peretto, P., Giachino, C., Panzica, G., \& Fasolo, A. (2001). Sexually dimorphic neurogenesis is topographically matched with the anterior accessory olfactory bulb of the adult rat. Cell Tiss Res, 306(3), 385-389.

Peroulakis, ME, Goldman, B, Forger, NG (2002), Perineal muscles and motoneurons are sexually monomorphic in the naked mole-rat (Heterocephalus glaber). $J$ Neurobiol, 51(1), 33-42.

Pfaus, JG, Heeb, MM (1997), Implications of immediate-early gene induction in the brain following sexual stimulation of female and male rodents. Brain Res Bull, 44(4): 397407. 
Pinheiro, AM, Pinto, L, Bessa, JM, Morais, M, Alves, ND, Monteiro, S, ... Sousa, N (2013), Sustained remission from depressive-like behaviour depends on hippocampal neurogenesis. Transl Psychiatr 3: e210.

Pravosudov, VV, Omanska, A (2005), Dominance-related changes in spatial memory are associated with changes in hippocampal cell proliferation rates in mountain chickadees. J Neurobiol 62(1): 31-41.

Rao, MS, Hattiangady, B, Abdel-Rahman, A, Stanley, DP, Shetty, AK (2005),Newly born cells in the ageing dentate gyrus display normal migration, survival and neuronal fate choice but endure retarded early maturation. Eur J Neurosci 21(2): 464-476.

Rasika, S., Nottebohm, F., \& Alvarez-Buylla, A. (1994). Testosterone increases the recruitment and/or survival of new high vocal center neurons in adult female canaries. Proc Natl Acad Sci U S A, 91(17): 7854-7858.

Rochefort, C, Gheusi, G, Vincent, JD, Lledo, PM (2002), Enriched odor exposure increases the number of newborn neurons in the adult olfactory bulb and improves odor memory. $J$ Neurosci 22(7): 2679-2689.

Ruiz-Gomez, MDL, Huntingford, FA, Øverli, Ø, Thörnqvist, PO, Höglund, E (2011), Response to environmental change in rainbow trout selected for divergent stress coping styles. Physiol Behav 102(3): 317-322.

Sapolsky, RM, Krey, LC, McEwen, BS (2002), The neuroendocrinology of stress and aging: the glucocorticoid cascade hypothesis. SAGE KE 2002(38): 21.

Sawamoto, K, Wichterle, H, Gonzalez-Perez, O, Cholfin, JA, Yamada, M, Spassky, N, AlvarezBuylla, A (2006) New neurons follow the flow of cerebrospinal fluid in the adult brain.Sci Signalling, 311(5761): 629.

Saxe, MD, Battaglia, F, Wang, JW, Malleret, G, David, DJ, Monckton, JE, ... Drew, MR (2006), Ablation of hippocampal neurogenesis impairs contextual fear conditioning and synaptic plasticity in the dentate gyrus. Proc Natl Acad Sci U S A 103(46): 17501-17506. 
Seney, M, Goldman, BD, Forger, NG (2006), Breeding status affects motoneuron number and muscle size in naked mole-rats: Recruitment of perineal motoneurons?. $J$ Neurobiol 66(12): 1354-1364.

Shapiro, LA, Ng, KL, Kinyamu, R, Whitaker-Azmitia, P, Geisert, EE, Blurton-Jones, M, ... Ribak, CE (2007a), Origin, migration and fate of newly generated neurons in the adult rodent piriform cortex. Brain Struct Funct 212(2): 133-148.

Shapiro, LA, Ng, KL, Zhou, QY, Ribak, CE (2007b), Olfactory enrichment enhances the survival of newly born cortical neurons in adult mice. Neuroreport, 18(10): 981-985.

Sherman, PW, Jarvis, JU, Alexander, RD (1991), Biology of the Naked Mole-rat. Monographs in Behaviour and Ecology.

Shors, TJ, Miesegaes, G, Beylin, A, Zhao, M, Rydel, T, Gould, E (2001), Neurogenesis in the adult is involved in the formation of trace memories. Nature, 410(6826): 372-376.

Simon, M, Czéh, B, Fuchs, E (2005), Age-dependent susceptibility of adult hippocampal cell proliferation to chronic psychosocial stress. Brain Res 1049(2): 244-248.

Smith, MT, Pencea, V, Wang, Z, Luskin, MB, Insel, TR (2001), Increased number of BrdUlabeled neurons in the rostral migratory stream of the estrous prairie vole. Horm Behav 39(1): 11-21.

Snyder, JS, Hong, NS, McDonald, RJ, Wojtowicz, JM (2005), A role for adult neurogenesis in spatial long-term memory. Neurosci, 130(4): 843-852.

Snyder, JS, Soumier, A, Brewer, M, Pickel, J, Cameron, HA (2011), Adult hippocampal neurogenesis buffers stress responses and depressive behaviour. Nature, 476(7361): 458461.

Spritzer, MD, Galea, LAM (2005), Androgens enhance cell survival but not cell proliferation in adult male rats. Horm Behav, 48: 129. 
Spritzer, MD, Galea, LA (2007), Testosterone and dihydrotestosterone, but not estradiol, enhance survival of new hippocampal neurons in adult male rats. Devel Neurobiol, 67(10): 1321-1333.

Sultan, S, Mandairon, N, Kermen, F, Garcia, S, Sacquet, J, Didier, A (2010), Learningdependent neurogenesis in the olfactory bulb determines long-term olfactory memory. FASEB J 24(7): 2355-2363.

Tabori, NE, Stewart, LS, Znamensky, V, Romeo, RD, Alves, SE, McEwen, BS, Milner, TA (2005), Ultrastructural evidence that androgen receptors are located at extranuclear sites in the rat hippocampal formation. Neurosci, 130(1): 151-163.

Tanapat, P, Hastings, NB, Reeves, AJ, Gould, E (1999), Estrogen stimulates a transient increase in the number of new neurons in the dentate gyrus of the adult female rat. $J$ Neurosci, 19(14): 5792-5801.

Tanapat, P, Hastings, NB, Gould, E (2005), Ovarian steroids influence cell proliferation in the dentate gyrus of the adult female rat in a dose-and time-dependent manner. J Compar Neurol, 481(3), 252-265.

Taliaz, D, Stall, N, Dar, DE, Zangen, A (2009), Knockdown of brain-derived neurotrophic factor in specific brain sites precipitates behaviours associated with depression and reduces neurogenesis. Molec Psychiatr 15(1): 80-92.

Thomas, RM, Hotsenpiller, G, Peterson, DA (2007), Acute psychosocial stress reduces cell survival in adult hippocampal neurogenesis without altering proliferation. $J$ Neurosci 27(11): 2734-2743.

Van Bokhoven, P, Oomen, CA, Hoogendijk, WJG, Smit, AB, Lucassen, PJ, Spijker, S (2011), Reduction in hippocampal neurogenesis after social defeat is long-lasting and responsive to late antidepressant treatment. Eur J Neurosci 33(10): 1833-1840.

Van der Hart, MGC, Czeh, B, De Biurrun, G, Michaelis, T, Watanabe, T, Natt, O, ... Fuchs, E (2002), Substance P receptor antagonist and clomipramine prevent stress-induced 
alterations in cerebral metabolites, cytogenesis in the dentate gyrus and hippocampal volume. Molecular Psychiatr 7(9): 933-941.

Wang, JM, Johnston, PB, Ball, BG, Brinton, RD (2005), The neurosteroid allopregnanolone promotes proliferation of rodent and human neural progenitor cells and regulates cellcycle gene and protein expression. J Neurosci, 25(19): 4706-4718.

Wilensky, AE, Schafe, GE, LeDoux, JE (2000), The amygdala modulates memory consolidation of fear-motivated inhibitory avoidance learning but not classical fear conditioning. $J$ Neurosci 20(18): 7059-7066.

Winocur, G, Wojtowicz, JM, Sekeres, M, Snyder, JS, Wang, S (2006), Inhibition of neurogenesis interferes with hippocampus-dependent memory function. Hippocampus 16(3): 296-304.

Yap, JJ, Takase, LF, Kochman, LJ, Fornal, CA, Miczek, KA, Jacobs, BL (2006), Repeated brief social defeat episodes in mice: effects on cell proliferation in the dentate gyrus. Behav Brain Res 172(2): 344-350.

Zhang, Z, Yang, R, Zhou, R, Li, L, Sokabe, M, Chen, L (2010), Progesterone promotes the survival of newborn neurons in the dentate gyrus of adult male mice. Hippocampus, 20(3): 402-412.

Zhou, S, Holmes, MM, Forger, NG, Goldman, BD, Lovern, MB, Caraty, A., ... \& Coen, CW (2013), Socially regulated reproductive development: Analysis of GnRH-1 and kisspeptin neuronal systems in cooperatively-breeding naked mole-rats (Heterocephalus glaber). J Comp Neurol. 


\section{Appendices}
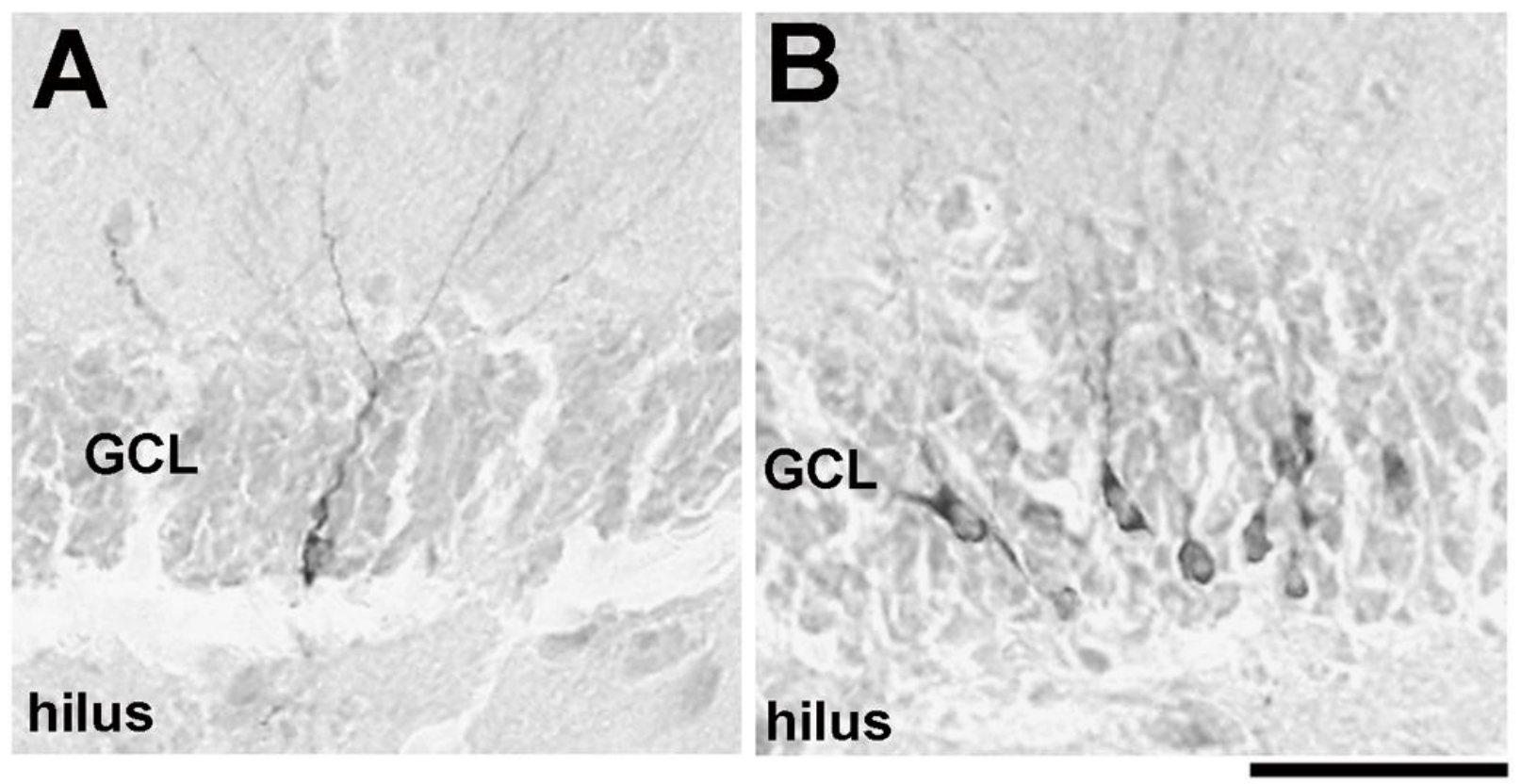

Figure 1. Photomicrographs of DCX immunoreactivity in the dentate gyrus of a breeding (A) and subordinate $(\mathrm{B})$ female naked mole-rat. $\mathrm{DCX}(+)$ cell bodies are evident in the subgranular zone and extend into the granule cell layer. Scale bar $=100 \mu \mathrm{m}$. 

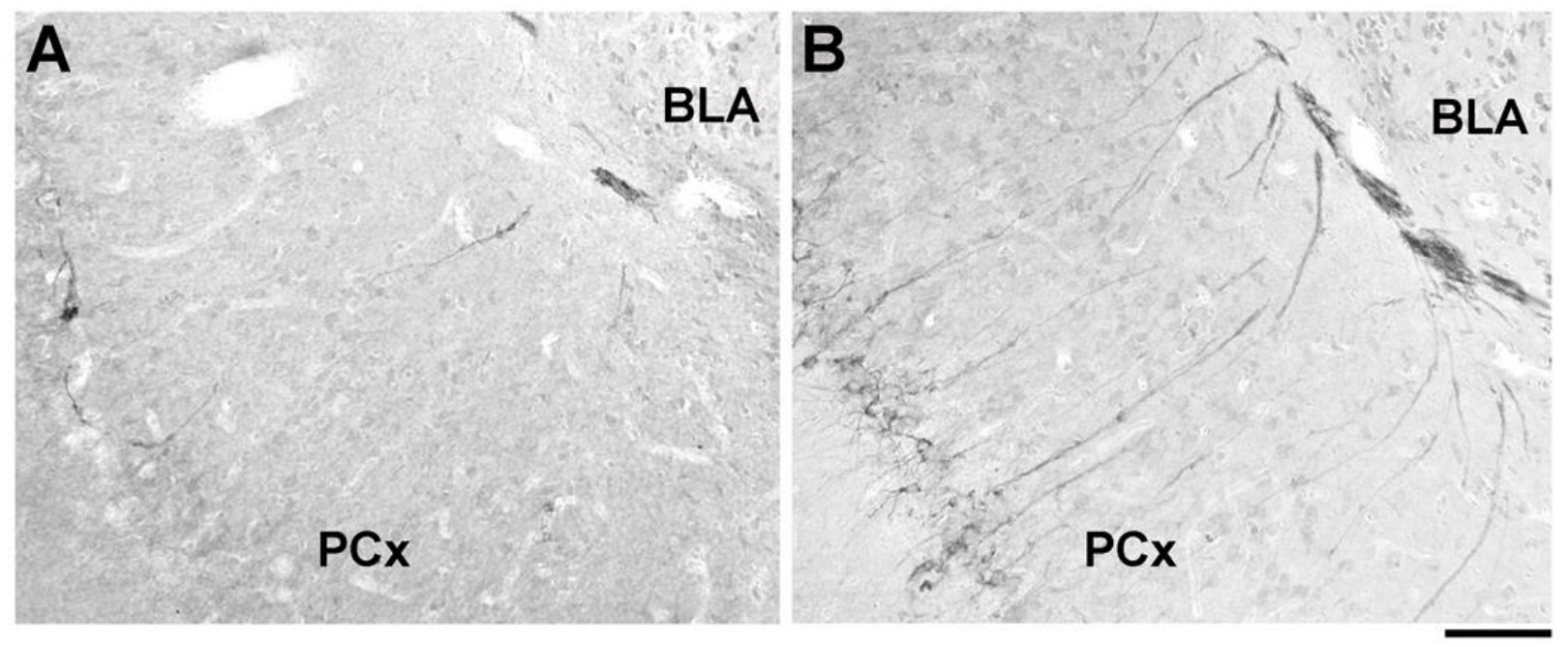

Figure 2. Photomicrographs of DCX immunoreactivity in the piriform cortex (PCx) and basolateral amygdala (BLA) of a breeding (A) and subordinate (B) female naked mole-rat. $\mathrm{DCX}(+)$ cell bodies are located in layer II of the PCx with $\mathrm{DCX}(+)$ processes present in layer III. Dense DCX label is evident at the border of the BLA in the subordinate (B). Scale bar $=200 \mu \mathrm{m}$. 


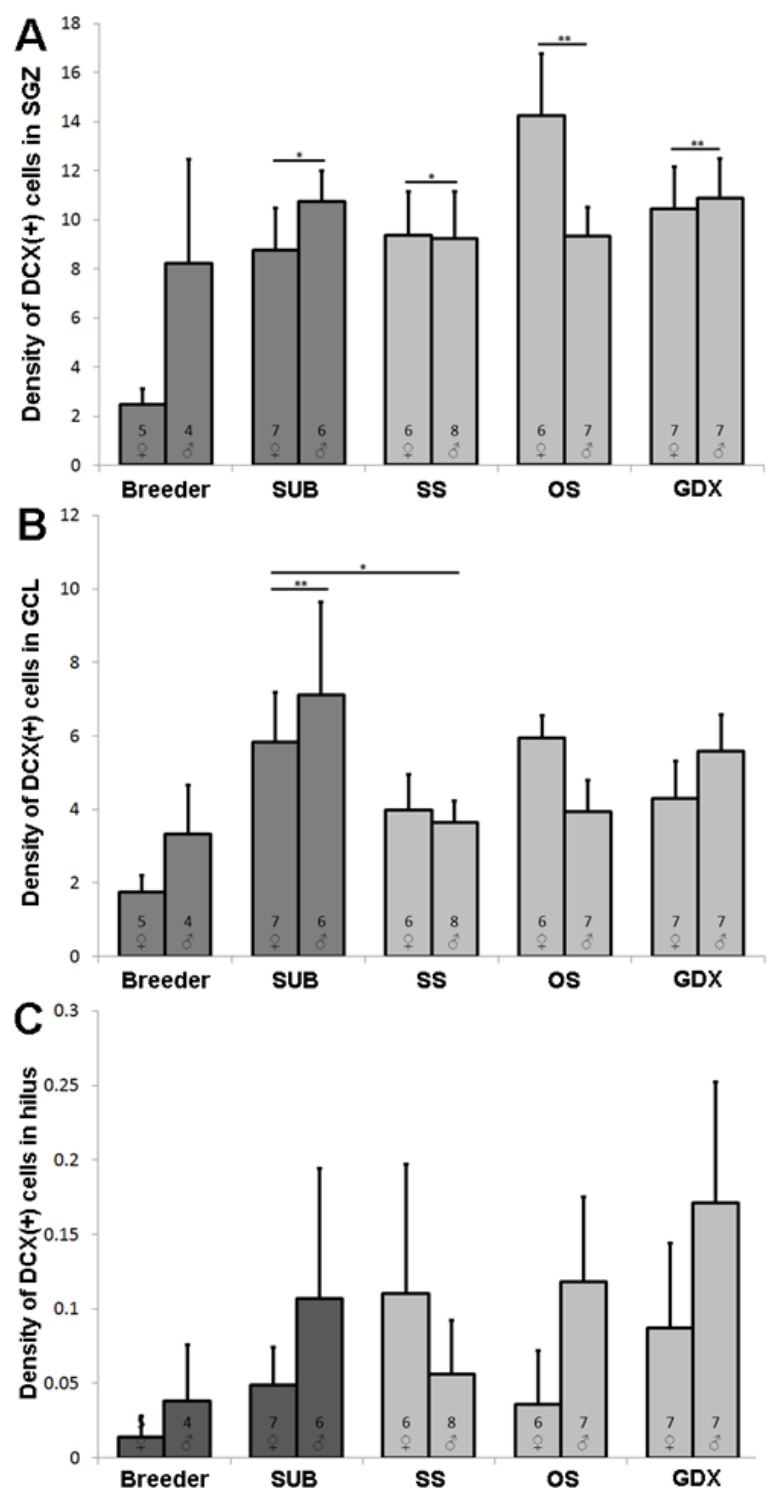

Figure 3. Social status influences hippocampal neurogenesis in the naked mole-rat. Mean (+ SEM) number of DCX(+) cells per section in the subgranular zone (SGZ; A), granule cell layer (GCL; B), and hilus (C) of the dentate gyrus. Breeders have reduced DCX labeling in the SGZ compared with all subordinate groups. DCX immunoreactivity in the GCL is higher in colonyhoused subordinates than breeder and SS groups. No significant effects were detected in the hilus. Dark grey bars represent colony-housed animals and light grey bars represent pair-housed animals. * indicates $\mathrm{p}<0.05$ and $* *$ indicates $\mathrm{p}<0.01$. OS $=$ opposite-sex, $\mathrm{SS}=$ same-sex, GDX = gonadectomised. 


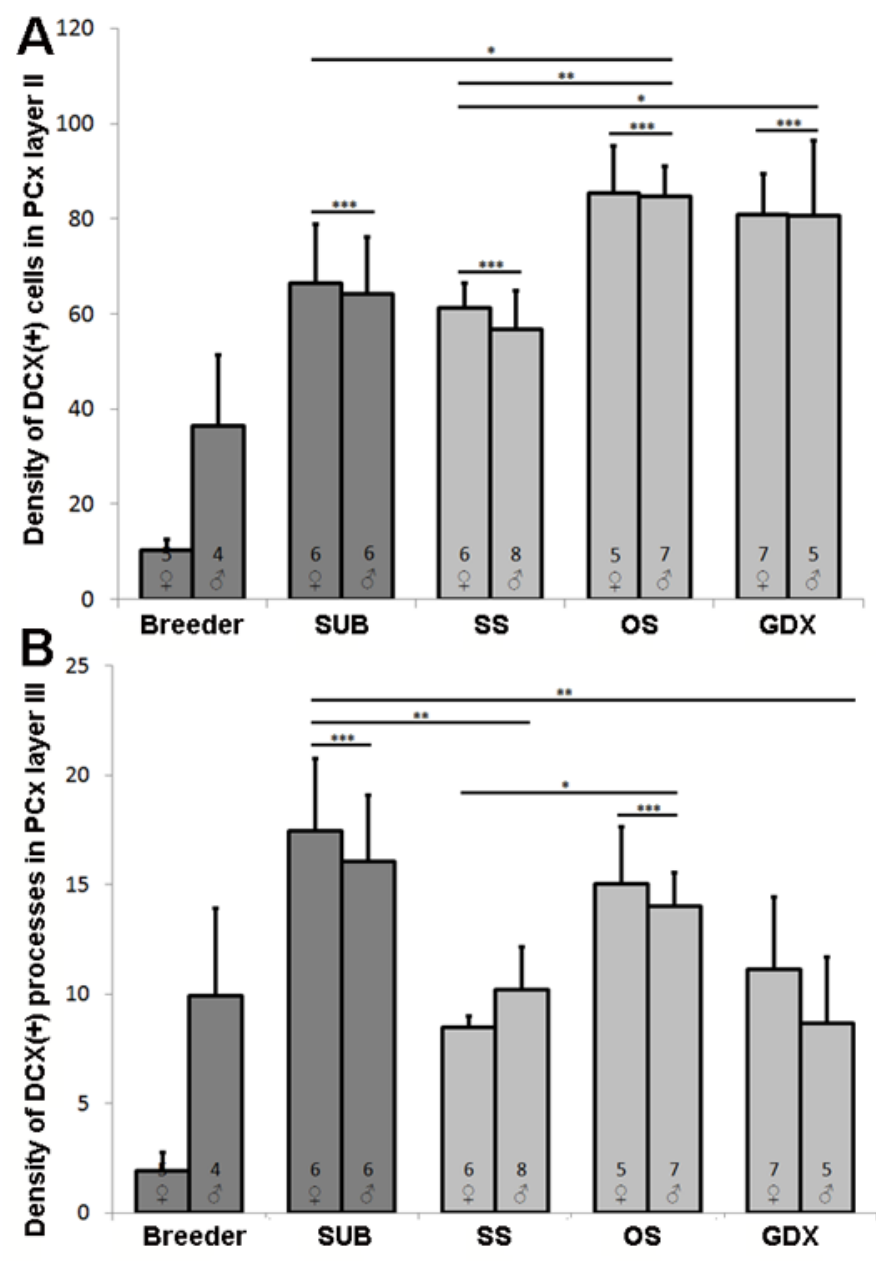

Figure 4. Social status and opposite-sex cues influence neurogenesis in the naked mole-rat piriform cortex (PCx). Mean (+SEM) number of DCX $(+)$ cells per section in (A) PCx layer II and DCX(+) processes per section in (B) PCx layer III. Breeders have lower DCX labeling in PCx layer II than all other groups. Among subordinates, OS and GDX labeling was comparable, with higher DCX immunoreactivity in OS animals than SUB and SS groups. In PCx layer III, Breeders have sparser DCX labeling than SUB and OS groups. For subordinates, SS animals have reduced DCX labeling relative to OS and SUB groups. Dark grey bars represent colonyhoused animals and light grey bars represent pair-housed animals. * indicates $\mathrm{p}<0.05$, ** indicates $\mathrm{p}<0.01$, and $* * *$ indicates $\mathrm{p}<0.001$. OS $=$ opposite-sex, $\mathrm{SS}=$ same-sex, GDX = gonadectomised. 


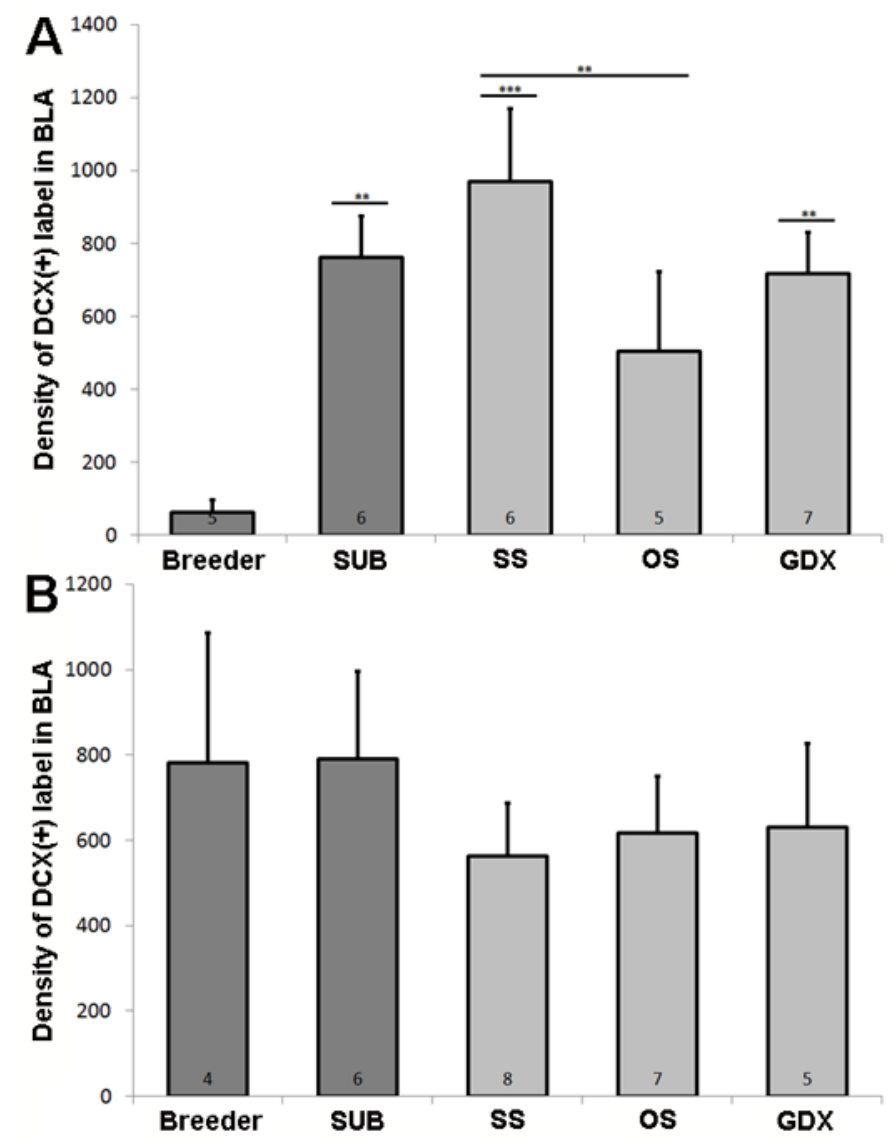

Figure 5. Social status influences neurogenesis in the basolateral amygdala of female naked mole-rats. Mean (+SEM) total surface area of DCX labeling $\left(\mu \mathrm{m}^{2}\right)$ per section in the BLA of (A) female and (B) male naked mole-rats. Queens have reduced DCX labeling in the BLA compared to SUB, SS, and GDX females. Furthermore, DCX immunoreactivity is higher in SS than OS females. No significant effects were detected for males. Dark grey bars represent colony-housed animals and light grey bars represent pair-housed animals. * indicates $\mathrm{p}<0.05$, ** indicates $\mathrm{p}<$ 0.01 , and $* * *$ indicates $\mathrm{p}<0.001 . \mathrm{OS}=$ opposite-sex, $\mathrm{SS}=$ same-sex, GDX $=$ gonadectomised. 